\title{
THE USE OF SILICONE OIL FOR MOBILISATION OF THE HAND
}

\author{
BASIL HELAL, ROBIN CHAPMAN, MARGARET ELLIS, DOREEN GIFFORD
}

From The London Hospital, London, and Chase Farm Hospital, Enfield

\begin{abstract}
When open wounds of the hand are treated in silicone oil baths there is a rapid increase in mobility and diminution of oedema. Silicone oil aids the separation of necrotic and infected tissue and assists the rapid formation of healthy granulation tissue, and thereby hastens healing.
\end{abstract}

Silicones are polymers with a structure consisting of alternate atoms of silicon and oxygen with hydrocarbon radicals attached to the silicon atoms. They were discovered by Frederick Stanley Kipping, Professor of Chemistry at University College, Nottingham (Challenger 1949). They have many uses in orthopaedic surgery (Helal 1969). The silicone fluids are clear liquids with an oily feel and a unique range of physical and chemical properties. They are insoluble in water to which they are highly repellent, non-adhesive, stable to heat and chemically non-reactive. The solubility of oxygen in the fluid is at least 10 times greater than in plasma or saline: a mouse when totally immersed can take enough oxygen to live for six hours (Clark and Gollan 1966). The simplest and commercially important group of silicones are dimethyl polysiloxanes, which have the formula:

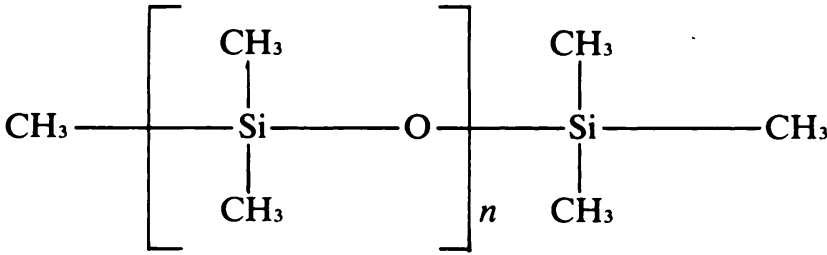

The longer the polymer chain is made, the more viscous the fluid becomes. The measure of the viscosity is known as the centistoke value, one centistoke being the viscosity of water. After experimenting with the material, 20-centistoke silicone was chosen as the most suitable viscosity for clinical use. The silicone fluids are non-toxic, non-irritating and non-sensitising to the skin (Levin 1958).

Gerow et al. (1963) performed an experimental study on burns in pigs in which they immersed the pigs in silicone. They demonstrated that normal pig skin would not macerate and that there was easy separation of the eschar and formation of a bed of thin granulation tissue, preventing infection in the burnt area. This experimental work is supported by two clinical studies. In the first, on burns of the hand (Miller, Hardy and Spira 1965), separation of the eschar appeared to occur sooner with this routine than with conventional methods of treatment and there was little stiffness or loss of movement by the time grafting was performed, even when tendons were exposed. In the second study Weeder, Brooks and Boyer (1967) found that the average time necessary for separation of the eschar was less than half that of conventional modes of treatment, and that the granulating surface effected by this method was flat, thin, healthy and accepted grafts readily. They concluded that patients thus treated required no narcotic analgesics and that patients with burnt extremities developed a full range of movement without pain within a few hours of immersion. Physical therapy was, therefore, markedly facilitated, thus preventing stiffness of the joints and contracture of the scar.

In 1968, on the basis of its success in the treatment of the burned hand, silicone oil was introduced at The London Hospital and Chase Farm Hospital for treating severe trauma of the hand.

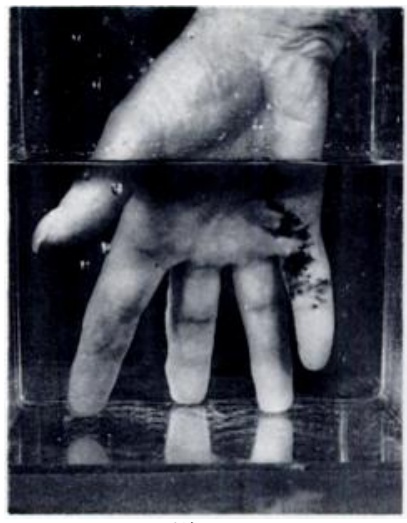

Fig. 1

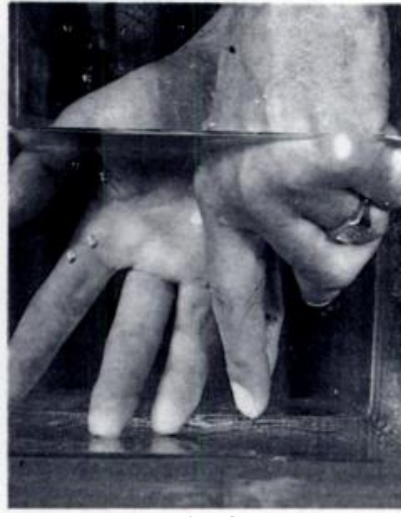

Fig. 2
Figure 1 -Active exercises in silicone oil. Figure 2-Passive exercises: self treatment.

\section{TREATMENT}

The hand is fully immersed in 20 -centistoke silicone (Dimethicone 20 produced by the Dow Corning Company). Active and passive exercises are then carried out for 15 to 20 minutes (Figs 1 and 2). These exercises are done from one to three times daily depending on the

B. Helal, MCh Orth, FRCS, Consultant Orthopaedic Surgeon $\}$ The London Hospital,

M. Ellis, MBAOT, District Occupational Therapist $\}$ Whitechapel, London E1 1BB, England.

D. Gifford, MCSP, Assistant Superintendent Physiotherapist, Chase Farm Hospital, Enfield, Middlesex, England.

R. H. Chapman, FRCS, Consultant Orthopaedic Surgeon, Kingston Hospital, Galsworthy Road, Kingston-upon-Thames, Surrey, England.

Requests for reprints should be sent to Mr B. Helal.

(C) 1982 British Editorial Society of Bone and Joint Surgery 0301-620X/82/1012-0067 \$2.00 
severity of the wound and whether the patient is an inpatient or an outpatient. An intelligent and cooperative patient can do them independently at home. When the therapist is controlling passive mobilisation, surgical gloves are worn to prevent cross-infection. After treatment a sterile dressing is wrapped around the hand. Any silicone on the raw areas should be left and the affected areas dressed according to the wishes of the surgeon in charge.

The silicone can be filtered of debris and resterilised by heating to 160 degrees Celsius for two hours. The temperature must be taken in the centre of the fluid as it is a good insulator. We have, however, not had cause to filter or sterilise the silicone in the course of any of the individual treatments undertaken. A container full of silicone usually lasts each patient for the complete treatment and then can be discarded. The approximate cost of the silicone oil for each patient is $£ 11.50$

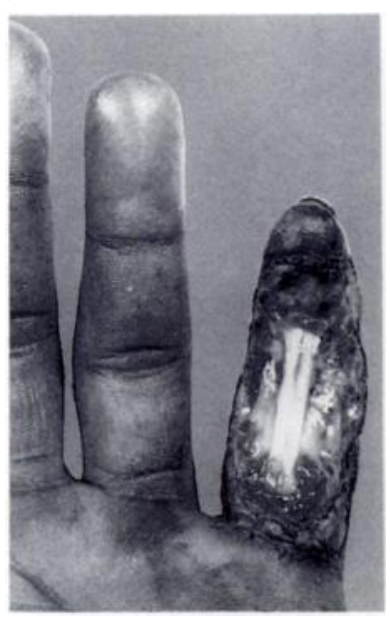

Fig. 3

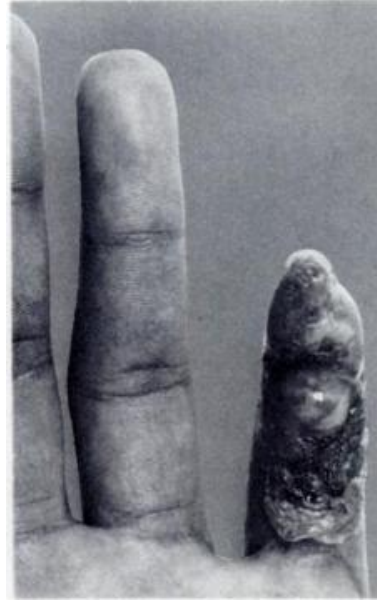

Fig. 4

\section{ILLUSTRATIVE CASE HISTORIES}

Case 1. A 22-year-old West Indian sustained a severe crush laceration of the left little finger. Silicone oil treatment was started. There was, later, a very large loss of soft tissue from the volar aspect of the finger. leaving the flexor tendons exposed and sloughing (Fig. 3). In view of the poor prognosis amputation was advised but refused by the patient. Silicone oil treatment was therefore continued with separation of slough, formation of granulations, and progressive healing of the skin (Fig. 4). Full skin cover was obtained with some fixed flexion at the terminal joint and good initial mobility of the proximal joint (Figs 5 and 6).

Case 2. A 28-year-old man fell and put his right hand into molten pitch. The hand was cleaned under general anaesthesia. There were patchy areas of full thickness burns. Mobilisation in silicone oil was commenced immediately and after three weeks' treatment there was good skin healing and good mobility.

Case 3. A 19-year-old man was involved in a road traffic accident and suffered loss of skin from the dorsum of his left hand caused by it being scraped along the road. The extensor tendons were exposed. The hand was cleaned under general anaesthesia at another hospital. Treatment in silicone oil was started 14 days later when he was first seen at The London Hospital (Fig. 7). There was complete skin healing and a full

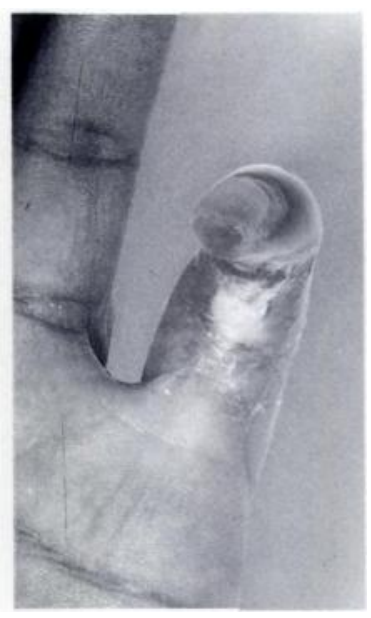

Fig. 5

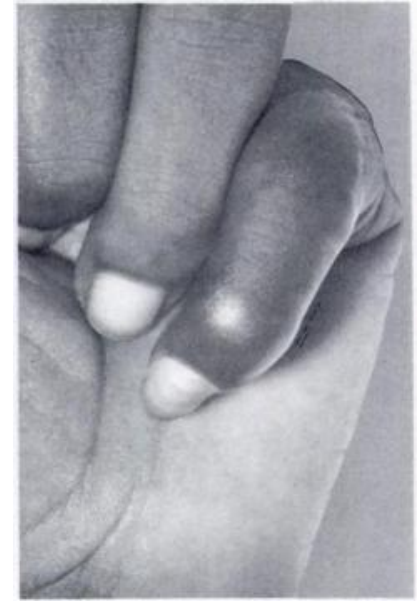

Fig. 6

Case 1. Figure 3-Left little finger with exposed and sloughing tendons. Figure 4-Progression of healing. Figures 5 and 6 -Sixteen weeks after injury.

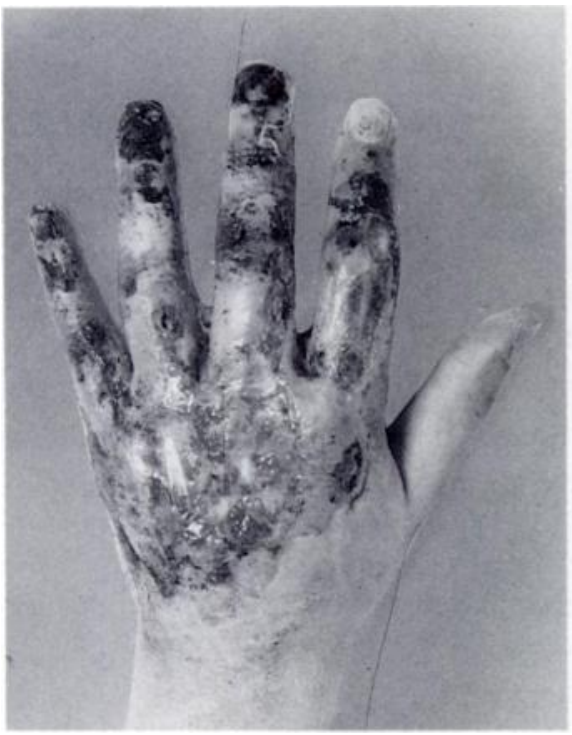

Fig. 7

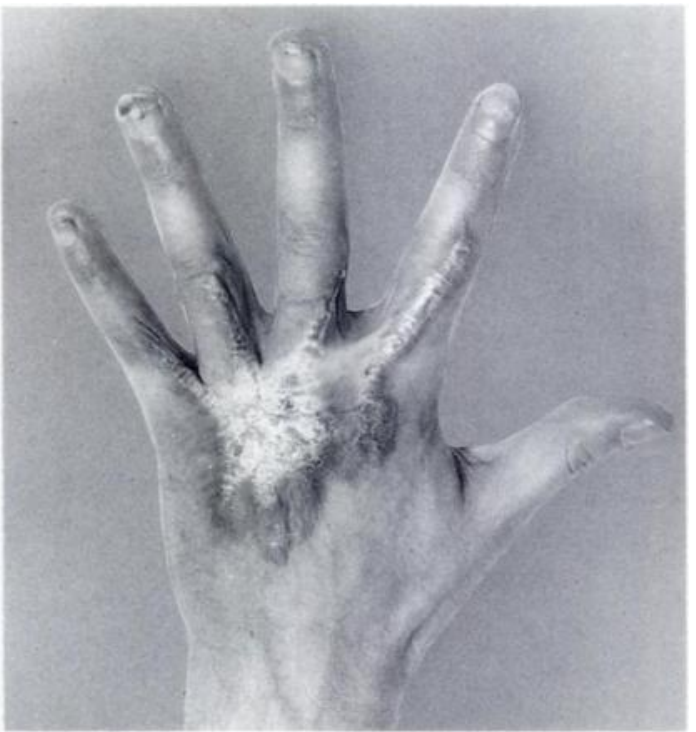

Fig. 8

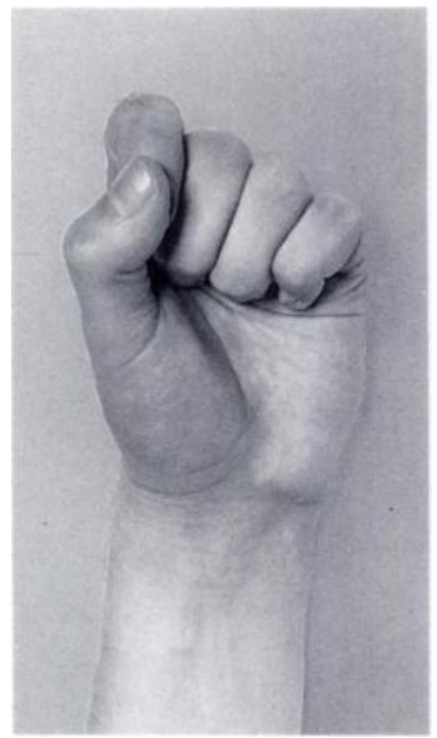

Fig. 9

Case 3. Figure 7-Appearance of the hand 14 days after injury and three days after the start of silicone oil treatment. Figures 8 and $9-$ Twelve weeks after injury. 


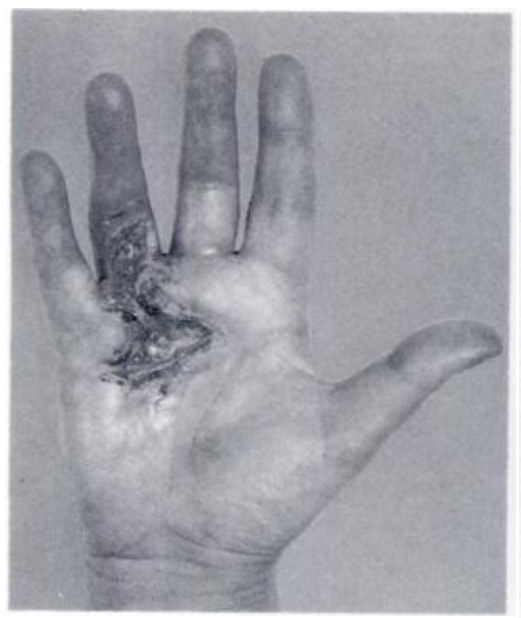

Fig. 10

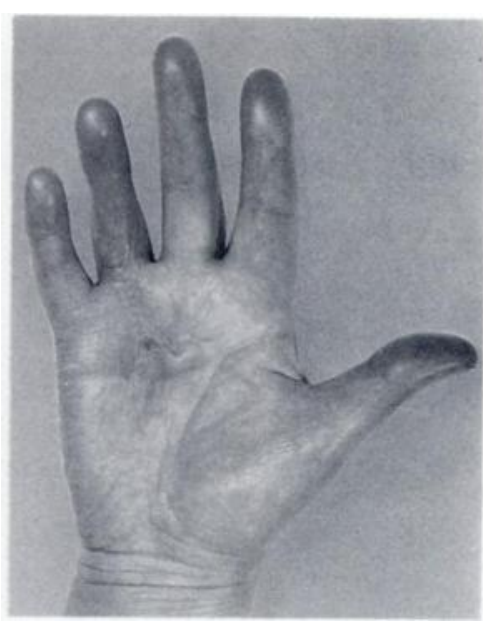

Fig. 11

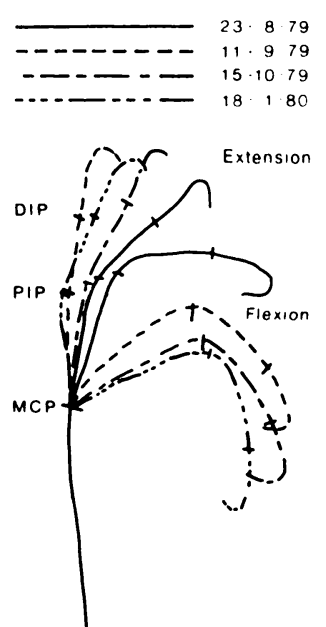

Fig. 12
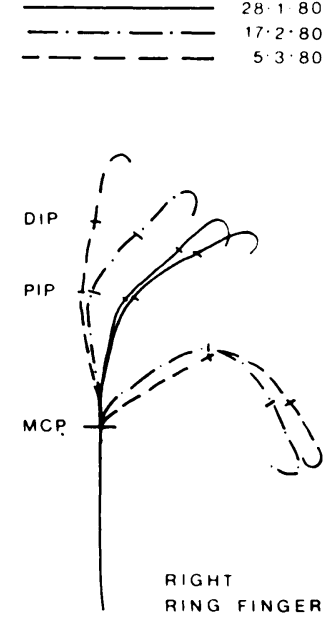

Fig. 13

Case 4. Figure 10-Appearance of the right hand 19 days after operation. Figure 11-Final appearance of the hand. Figures 12 and 13-Odstock tracings showing progression of range of active flexion and extension of the ring finger.

range of movement of the fingers except for the proximal interphalangeal joint of the index finger which had been destroyed at the time of his injury (Figs 8 and 9).

Case 4. A 54-year-old woman was operated on for a severe Dupuytren's contracture involving the right ring finger. The diseased fascia was excised from the palm, this incision being left open as described by McCash (1964). The Dupuytren's cord was excised from the ring finger using a straight incision with Z-plasties. A good correction was obtained. Silicone oil treatment was started three days later. There was later breakdown of the wound with loss of the skin edges as shown (Fig. 10). Skin grafting was considered but it was decided just to continue mobilisation in silicone oil and use an Odstock splint (Glanville 1962) to hold the correction; the wound healed in five weeks. The final result is shown in Figure 11 and the Odstock tracings in Figures 12 and 13.

Case 5. An 18-year-old man injected car sealant at high pressure into the base of his right index finger. Six days later he was admitted with a massively swollen septic finger. Wide decompression of the whole flexor aspect of the finger and palm of the hand was performed down to the tendon sheath and large amounts of pus were released. The dorsal aspect of the hand was also decompressed and again large amounts of pus were released. Both wounds were left open. Twelve days later mobilisation in silicone oil was started and after three weeks' treatment the proximal wound had healed, but there was a septic slough over the proximal interphalangeal joint and the tendon in the base was necrotic. Treatment with silicone was continued and the wound continued to heal. Eight weeks after the start of the silicone treatment the wound was completely healed. A 20-degree flexion contracture at the proximal interphalangeal joint was corrected using an Odstock extension splint. One year after injury there was a full range of movement apart from a 15-degree loss of full extension at the terminal joint.

\section{DISCUSSION}

These examples demonstrate the type of wounds for which mobilisation in silicone oil can be a useful adjunct to the usual therapy. A large number of such cases have now been treated in this way. During 197945 patients were treated in the two hospitals. Their injuries fell into five categories: severe crush injuries with open wounds; loss of soft tissue with some tendons exposed; infected wounds; open wounds resulting from procedures for Dupuytren's contracture; and burns.

Silicone oil provides a non-irritant, bland, air-free medium in which the hand can be exercised with less pain than would otherwise occur. This enables patients to obtain a good range of movement at an earlier stage of treatment. It prevents drying out of the tissues and helps in the separation of necrotic and infected tissue, thus assisting in the formation of healthy granulation tissue. The clinical impression gained is that it speeds up the time taken for these wounds to heal, and in many patients the need for further surgical treatment such as skin grafting has been avoided.

\section{REFERENCES}

Challenger F. Obituary: Professor FS Kipping FRS. Nature 1949;164:93-4.

Clark LC Jr, Gollan F. Survival of mammals breathing organic liquids equilibrated with oxygen at atmospheric pressure. Science 1966:152:1755-6.

Gerow FJ, Hardy SB, Spira M, Law SW. Immersion treatment for burns: an experimental study. Surg Forum 1963;14:32-3.

Glanville HJ. A versatile "lively" splint. Lancet 1962;i:252-3.

Helal B. Silicones in orthopaedic surgery. In: Apley AG, ed. Recent advances in orthopaedic surgery. London: J \& A Churchill Ltd, 1969:91-114.

Levin R. The pharmacy of silicones and their uses in medicine. London: Morgan Brothers Lid, 1958:28-9.

Miller J, Hardy SB, Spira M. Treatment of burns of the hand with silicone dressing and early motion: preliminary report.J Bone Joint Surg [Am] 1965;47-A:938-43.

McCash CR. The open palm technique in Dupuytren's contracture. Br J Plast Surg 1964;17:271-80.

Weeder RS, Brooks HW, Boyer AS. Silicone immersion in the care of burns. Plast Reconstr Surg 1967;39:256-62. 